Linguagem em (Dis)curso - LemD, v. 8, n. 3, p. 467-485, set./dez. 2008

\title{
A INTERTEXTUALIDADE NA LEITURA DA ALFABETIZADORA
}

Cosme Batista dos Santos*

\begin{abstract}
Resumo: Este artigo apresenta um estudo dos mecanismos lingǘsticos e cognitivos envolvidos na construção da definição da 'intertextualidade' por uma professora alfabetizadora em formação. O pressuposto adotado é o de que a retextualização de textos escritos da ciência e da divulgação científica nos eventos de formação implica em reformulação, apropriação e representação social dos objetos teóricos em função das particularidades do contexto enunciativo. Nessa perspectiva, portanto, a análise de um evento de letramento específico da formação do professor, que visa ao ensinoaprendizagem de conceitos ou de definições teóricas, pode ser orientada pela seguinte questão: quais os mecanismos lingüísticos empregados pelo professor em formação para tornar mais familiares as noções teóricas na Universidade? Desse modo, essa análise pode ser desenvolvida com o intuito de ampliar descobertas anteriores sobre a representação social de termos teóricos realizada pelo professor. Trata-se de uma discussão sobre a participação da oralidade e da experiência na aprendizagem da definição especializada..

Palavras-chave: letramento; retextualização; representação social; enunciação; intertextualidade.
\end{abstract}

\footnotetext{
* Professor da Universidade do Estado da Bahia, Campus III. Pesquisador do núcleo de estudos em Letramento do Professor (NL/IEL/UNICAMP) e coordenador do projeto de pesquisa Letramento de Professores Alfabetizadores no Semi-árido (PROLETRA/UNEB/DCH III). Doutor e mestre em Lingüística Aplicada. E-mail:<cosmebs@uol.com.br>.
} 
[...] a cultura oral tornou-se o alvo de uma escrita que devia educá-la ou informá-la. Os participantes foram transformados em supostos consumidores passivos. Não obstante, os elementos que julgávamos eliminados continuaram a determinar as mudanças sociais e a organizar a maneira de 'receber' as mensagens culturais, isto é, transformá-la pelo uso que dela se faz.

(Michel de Certeau e Luce Giard, Por uma ciência prática do singular)

\section{INTRODUÇÃO}

Este artigo investiga o letramento e a formação lingüística do professor alfabetizador, focalizando a apropriação do conceito de 'intertextualidade' acessado através de gêneros escritos formadores, particularmente em aulas universitárias de um curso de Pedagogia para as séries iniciais. ${ }^{1}$ De maneira ainda mais específica, este trabalho investiga a formação da alfabetizadora, considerando as mudanças lingüísticoenunciativas e cognitivas implicadas na retextualização ou na passagem da definição do conceito de 'intertextualidade' dos gêneros acadêmicos para as manifestações orais de uma alfabetizadora sobre as aulas de leitura nas séries iniciais do ensino fundamental I, da rede municipal de educação de Mairi, no estado da Bahia.

O pressuposto inicial assumido neste trabalho é o de que a retextualização (MARCUSCHI, 2001; MATÊNCIO, 2003) de definições de termos dos textos científicos ou mesmo de termos de textos da divulgação científica para outras instâncias de uso dessas definições ou conceitos é sempre marcada por uma reconfiguração simbólica desses conceitos. Determinados estudos sobre a reformulação científica, sob a perspectiva da teoria da enunciação, mostram que a passagem das definições especializadas para os usos sociais, especialmente em manifestações orais cotidianas ou produzidas em contextos não

\footnotetext{
${ }^{1}$ Curso de formação inicial em pedagogia para alfabetizadores, que está sendo oferecido pelo Programa REDE UNEB da Universidade do Estado da Bahia - UNEB.
} 
marcados pela tensão do saber-fazer-dizer acadêmico, envolve variadas operações de reformulação (JACOBI, 1984; BREY, 1984). Essas operações, por sua vez, são amplamente determinadas pelos efeitos das particularidades do contexto enunciativo e do uso que os novos usuários fazem desses conceitos e definições, resultando em uma apropriação das categorias especializadas da ciência lingüística (SANTOS, 2005).

É importante acrescentar ainda que este trabalho não desconsidera o impacto das práticas letradas acadêmicas na produção de novas maneiras de dizer, uma vez que há evidências de que as alfabetizadoras em formação também tendem a estabilizar categorias das definições especializadas em resumos e, especialmente, em outras produções práticas que mostram o resultado da participação em práticas letradas acadêmicas ou nas rotinas da educação superior. O objetivo deste artigo é inter-relacionar e discutir o efeito das condições de recepção, visando a examinar o que, de fato, as alfabetizadoras em formação fazem com as definições teóricas que recebem nos cursos universitários, em situações mais espontâneas de uso do conhecimento aprendido a partir da escrita acadêmica, como ocorre com o uso da definição de 'intertextualidade' pela alfabetizadora em sua prática escolar, tal como é examinada neste artigo. Em síntese, interessa saber o que a alfabetizadora faz com a definição de 'intertextualidade' ensinada na Universidade, particularmente quando esta é atualizada no uso oral e em práticas cotidianas.

As descobertas acerca das modalidades e dos mecanismos de definição da intertextualidade, assim como de outras noções lingüísticas retextualizadas dos enunciados escritos da formação para os enunciados orais cotidianos, poderão apoiar discussões futuras acerca da avaliação do impacto dos enunciados escritos na formação, levando em conta modos situados de recepção e de aprendizagem do saber especializado. Especialmente, porque o estudo da recepção oral dos conteúdos da formação universitária permite levar em consideração uma perspectiva não dicotômica da relação letramento-oralidade, além de redimensionar a avaliação do impacto social da formação superior em contextos minoritários, sobretudo quando esta se restringe à avaliação das práticas de letramento realizadas estritamente na esfera acadêmica.

$\mathrm{O}$ artigo está organizado a partir dos seguintes tópicos: referencial teórico, destacando os conceitos de letramento, de retextualização e de 
representação na perspectiva sociodiscursiva; metodologia utilizada para geração de dados, destacando as contribuições da lingüística aplicada e da pesquisa qualitativa na investigação acerca do impacto social da escrita e dos conceitos especializados na formação do alfabetizador; análise dos dados, destacando os mecanismos lingüísticos implicados na representação e apropriação do conceito de 'intertextualidade' pelo alfabetizador e, finalmente, as considerações finais.

\section{LETRAMENTO: DA RETEXTUALIZAÇÃO ÀS REPRE- SENTAÇÕES SOCIAIS}

Neste artigo, o letramento é entendido como uma prática social mediada por gêneros discursivos escritos e específicos (KLEIMAN, 1995; BARTON; HAMILTON, 1998). Acrescentamos, a essa perspectiva, que o letramento pode ser considerado tanto como o resultado do impacto da tecnologia e da escrita na mudança cognitiva dos indivíduos ou grupos social e culturalmente situados (OLSON, 1995; GOODY; WATT, 2006), como também o efeito das condições de recepção das definições, considerando a especificidade dos enunciados orais e das definições ordinárias (RIEGEL, 1987), os conhecimentos prévios e práticos, as motivações ideológicas, além de outras particularidades enunciativas que interferem na reconfiguração simbólica do saber sobre a escrita e das definições e conceitos que se fazem circular, por meio dela, na sociedade, na universidade e na escola.

O estudo minucioso das operações que envolvem a difusão e recepção do conceito, sobretudo na atividade discursiva que se desenvolve no interior de uma prática social de letramento, deve levar em conta os mecanismos de retextualização da escrita para a fala - escrita $\rightarrow$ fala - isto é, os mecanismos lingüístico-enunciativos implicados na passagem dos textos escritos, ou de suas partes, para os textos orais (MARCUSCHI, 2001). Trata-se, portanto, de um conceito importante para o estudo das operações de transformação de textos e de definições formadores em outros textos, em práticas e eventos específicos de letramento (MATÊNCIO, 2003) e para o estudo discursivo da inserção dos professores alfabetizadores em práticas letradas de prestígio, 
inclusive as práticas de formação lingüística na universidade (SANTOS, 2003; SANTOS, 2005).

Para ampliar o foco na retextualização de conceitos da escrita para os modos de ancoragem desses conceitos na oralidade, o estudo também se apóia no conceito de representação social, definindo-o como o conhecimento prático, ordinário, que determinados indivíduos ou grupos culturalmente situados produzem e manifestam nas interações sociais cotidianas (ABRIC, 1994; JODELET, 2001). A nosso ver, esses conceitos configuram uma base heurística importante para os estudos do letramento do professor, sobretudo os que se interessam pelos contextos minoritários, pelo uso social e situado da escrita e dos conceitos e, fundamentalmente, os estudos que se interessam pelos problemas relacionados com a educação intercultural que, por sua vez, incluem a relação entre o saber científico e o saber prático dos alfabetizadores em formação.

Em uma formulação mais recente do conceito, as representações são consideradas como objetos dos discursos ou das práticas discursivas (ABRIC, 1994; PY, 2000; PY, 2004). Dessa forma, a significação de uma representação social é determinada pelo contexto social, isto é, "pelo contexto ideológico e pelo lugar ocupado no sistema social pelo indivíduo ou pelo grupo social concernido", e pelo contexto discursivo, isto é, "pela natureza das condições imediatas de produção" (ABRIC, 1994). Na perspectiva sociodiscursiva, ainda, as representações dos alfabetizadores em formação acerca das definições científicas podem aparecer nos discursos sob a forma de uma representação de referência, ou seja, estabilizando elementos que identificam as crenças, as posições socialmente consolidadas, muitas vezes, como herança da história da formação universitária, da formação continuada e de outras leituras que constituem o consenso acadêmico-social acerca dos conceitos especializados. Da mesma forma, a representação pode aparecer sob a forma de uma representação de/em uso, ou seja, acrescentando elementos que desestabilizam as crenças, as posições cristalizadas e pré-construídas acerca dos objetos de representação (PY, 2000).

Em um estudo que realizamos sobre a formação lingüística (SANTOS, 2005), por exemplo, mostramos que o conceito da coerência textual faz parte do repertório de saber lingǘstico estabilizado nos 
currículos e nas rotinas de formação do alfabetizador em diferentes contextos institucionais. 2 Trata-se, dessa forma, de um saber coletivo partilhado por diferentes especialistas, formadores e educadores; no entanto, nas práticas discursivas esse saber passa por mudanças contínuas, especialmente sob a influência das interações e dos usuários específicos. Nesse sentido, a definição da coerência adquire um tipo de configuração lexical, quando é manifestada em uma aula universitária, e terá outro tipo de configuração lexical, quando é manifestada em uma aula de produção textual para crianças. Essa instabilidade discursiva, que resulta em mudanças simbólicas do enunciado definidor, também, permite estabilizar um sentido que é coletivamente partilhado com o que chamamos de coerência do texto.

Em outros termos, a nossa análise mostra que a desestabilização dos enunciados definidores aqui focalizados não resulta em um apagamento da representação de referência (RR), e que a representação em uso (RU) tende a ser discursivamente marcada por inovações simbólicas, por categorizações ordinárias e cotidianas que fazem com que o conceito de referência perca estabilidade simbólica e sua definição científica seja enriquecida a partir de novas imagens e de novas seqüências definidoras.

A rigor, devemos investigar, a partir de evidências qualitativas, em que medida os enunciados definidores especializados desestabilizam ou não as definições cotidianas e ordinárias dos professores em formação. Para isso, é preciso evidenciar, por exemplo, os elementos (nomes, seqüências, sentidos, etc.) que se mantêm nos enunciados definidores em uso, formando uma rede ou sistema minimamente estável e que dão alguma identidade às representações dos sujeitos pesquisados. As categorizações e seqüências estáveis dali resultantes são, portanto, o resultado de um conflito cognitivo típico da comunicação intercultural e da aprendizagem em geral. Essas evidências nos levam a reiterar que o letramento envolve tanto o que a escrita faz com os seus usuários, proporcionando, por exemplo, o acesso a novos enunciados e conceitos, quanto o que esses mesmos usuários fazem com a escrita e com os seus

\footnotetext{
2 A grande maioria dos projetos de formação continuada em linguagem para alfabetizadores tem como base os pressupostos da lingǘstica textual e especialmente os conceitos de coerência e coesão textuais.
} 
conceitos em práticas sociais e em eventos específicos, também a partir das suas necessidades específicas.

\section{METODOLOGIA, GERAÇÃO DE DADOS E OUTRAS CONSIDERAÇÕES}

Os dados deste artigo foram gerados a partir da orientação da lingüística aplicada como campo de pesquisa, valorizando a pesquisa sobre a linguagem nos usos e nas práticas social e culturalmente situadas (KLEIMAN, 1998; CAVALCANTI, 1998). Mais explicitamente, as pesquisas acerca da recepção dos conceitos pelo alfabetizador, sob essa orientação, apresentam pelo menos duas características importantes: (i) valorização das condições reais e das práticas discursivas em que as representações são manifestadas; (ii) valorização da diversidade dos enunciados, das modalidades e demais elementos dos contextos enunciativos em que as representações são formuladas.

Em função dessas características, o pesquisador do letramento e das representações sociais como objetos das práticas discursivas deve mobilizar as estratégias de um bricoleur, ou seja, deve fazer uso de diversos instrumentos, visando a tornar o objeto mais evidente, além disso, deve se predispor a reconstruir pressupostos e redefinir o quadro conceitual ao longo da realização da pesquisa. Esse modelo de investigação está associado também às pesquisas do tipo qualitativo, uma vez que a nossa perspectiva é analisar as seqüências definidoras implicadas na recepção de conceitos de formação, focalizando as evidências qualitativas que possam marcar diferenças e semelhanças entre as definições formadoras e as definições dos alfabetizadores focalizados na pesquisa.

Com base nesta orientação metodológica, os dados considerados para este trabalho foram os textos escritos, especialmente os livros estudados em aulas universitárias das disciplinas de Lingüística e de Metodologia do Ensino da Língua Portuguesa, em que a definição de 'intertextualidade' era um dos objetos da formação lingüística dos alfabetizadores. Além disso, focalizamos a retextualização (escrita $\rightarrow$ fala) 
da definição de 'intertextualidade' - objeto de formação lingüística - dos textos escritos para a fala de uma alfabetizadora em situação escolar.

\section{A DEFINIÇÃO DE 'INTERTEXTUALIDADE' NOS TEXTOS ESCRITOS FORMADORES}

Os textos escritos formadores, que permitem o acesso à formação lingüística da alfabetizadora, nesta pesquisa, são dois livros: o livro $O$ intertexto escolar: sobre a leitura, a aula e redação, do autor Samir Meserani (doravante TF1) e o livro Leitura e interdisciplinaridade: tecendo redes nos projetos da escola, de Angela B. Kleiman e Silvia E. Moraes (doravante TF2).

Em TF1, a intertextualidade é definida através de seqüências lexicais definidoras, tais como, "relação dialógica entre os textos" ou, simplesmente, "relação entre os textos". Essas seqüências aparecem, por exemplo, na definição direta "a intertextualidade é uma expressão do léxico atual da literatura, criada pela semioticista Júlia Kristeva, para designar o fenômeno da relação dialógica entre os textos" (MESERANI, 2002, p. 63) e, ainda, no caso específico desse texto formador, em definições indiretas do tipo "a afirmação da existência de relações entre textos escritos, principalmente literários, não é nova" (MESERANI, 2002, p. 64).

Em TF2, a definição mais recorrente de 'intertextualidade' é manifestada a partir de seqüências lexicais do tipo "interseção com outros textos" e "relações entre os textos", como se pode constatar em "o significado de um texto não se limita ao que apenas está nele; seu significado resulta da interseção com outros. Assim, o conceito de 'intertextualidade' refere-se às relações entre os diferentes textos [...]" (KLEIMAN; MORAES 1999, p. 62).

Considerando apenas os textos escritos formadores, podemos perceber uma tendência à estabilização da seqüência definidora "relação entre os textos", especialmente nos enunciados que contêm uma definição direta do tipo $x$ é $y$, em que o termo a ser definido x é ligado diretamente por uma categoria semanticamente equivalente $y$ (RIEGEL, 1987). Estudos no âmbito da reformulação científica mostram que as 
definições diretas são normalmente empregadas nos textos escritos, particularmente nas obras de divulgação científica e de semidivulgação científica (LOFFLER-LAURIAN, 1984). ${ }^{3}$

A seqüência definidora da 'intertextualidade', "relação entre os textos", também é empregada em outras obras da divulgação científica e da semidivulgação científica, específicas da lingüística do texto e da análise do discurso. No livro Introdução à análise do discurso, de Helena Brandão, essa seqüência é empregada, especialmente, no enunciado definidor "a noção de intertextualidade abrange os tipos de relações intertextuais definidas como legítimas que uma formação discursiva (FD) mantém com outras" (BRANDÃO, 1996, p. 760). E, ainda, no livro O texto e a construção dos sentidos, de Ingedore Koch, essa seqüência é empregada, especialmente, no enunciado definidor "a intertextualidade em sentido restrito é a relação de um texto com outros textos previamente existentes" (KOCH, 1997, p. 48). Isso vale dizer que, embora as teorias e abordagens sejam diferentes (teorias do texto e teorias do discurso), a seqüência relação entre os textos se estabiliza nos enunciados definidores da 'intertextualidade'.

\section{A DEFINIÇÃO DA 'INTERTEXTUALIDADE' NO TEXTO ORAL DA ALFABETIZADORA}

Nesta parte, serão mostrados e analisados os mecanismos lingüístico-enunciativos e cognitivos, tal como foi indicado na introdução, que estão implicados na apropriação do conceito de 'intertextualidade' pela alfabetizadora. O enunciado definidor da alfabetizadora, como já foi sinalizado, foi gerado a partir de uma entrevista semi-estruturada, como resposta à pergunta o que você

\footnotetext{
3 Os textos de semidivulgação científica ou semivulgarização científica proporcionam uma popularização cientifica intermediária entre a ciência - diálogo entre o cientista e os cientistas - e a divulgação científica - diálogo entre o cientista e o grande público. A rigor, trata-se de um tipo de popularização científica muito valorizada nos cursos de graduação e na formação continuada de professores, por exemplo, por meio de livros técnicos. A semidivulgação científica é feita normalmente pelo próprio cientista, enquanto que a divulgação científica ou a vulgarização científica propriamente dita é feita normalmente pelo jornalista. Outras informações relacionadas ao assunto podem ser conhecidas a partir de Loffler-Laurian (1983 e 1984).
} 
entende por intertextualidade? (VELOSO, 2006). Evidentemente, essa questão é parte de um conjunto de outras que visavam conhecer a história de letramento e de formação da professora entrevistada: cursos e leituras realizadas, atuação docente, etc, sem perder de vista a sua participação no curso de formação lingüística mencionado anteriormente. ${ }^{4}$

No enunciado, abaixo, a alfabetizadora define a intertextualidade, atendendo de imediato a expectativa posta na pergunta. A resposta da professora gerou a seguinte definição:

[...] a intertextualidade... no meu entendimento... é o conhecimento prévio é um texto fazendo relações a outros textos...é no caso está sempre ligando... pra gente fazer uma escrita devemos ter conhecimento de outros textos... de outra escrita que já vimos... ...venho sempre explorando com o educando se eles já ouviram outra informação parecida com aquele texto que estamos lendo [...]

No enunciado, acima, diferentemente de como ocorre nos enunciados escritos formadores, a 'intertextualidade' é definida a partir de uma semiologia lingüística mais próxima das definições ordinárias, ou seja, não segue em todas as suas ocorrências a ordem canônica e objetiva do esquema $x$ é $y$ (RIEGEL, 1987), tal como tende a ocorrer, especialmente, nos textos escritos de formação. Na definição ordinária, o enunciado definidor contém modalizações, repetições, acréscimos e outros mecanismos lingüístico-enunciativos mais empregados na modalidade oral e no discurso cotidiano e, efetivamente, sob a influência das especificidades do contexto enunciativo.

De início, a definição é introduzida pela modalização discursiva "no meu entendimento". Este modalizador marca formalmente o lugar do sujeito do discurso, ou seja, o lugar do sujeito que possui e assume um entendimento e um dizer sobre a intertextualidade. Evidentemente, essa marca não assegura, em termos absolutos, uma responsabilidade do sujeito sobre o sentido do dizer, apenas uma atitude, uma posição

\footnotetext{
4 A entrevista completa foi realizada, sob a nossa orientação, por Adinaloi Veloso, bolsista de Iniciação Científica do Programa de Iniciação Científica da Universidade do Estado da Bahia UNEB, no período de agosto de 2005 a dezembro de 2006, especialmente no município de MairiBa.
} 
assumida no discurso (MAINGUENEAU, 2001) sobre um entendimento possível. Trata-se, a rigor, de uma voz que assume uma definição e um modo de definir o objeto em questão e, ao mesmo tempo, retira o valor de verdade eterno e universal dos enunciados definidores não modalizados.

No referido enunciado, ainda, a definição de intertextualidade é manifestada por meio de 4 (quatro) seqüências definidoras mais recorrentes nos enunciados gerados no âmbito da comunicação científica a respeito desse conhecimento. As duas primeiras seqüências mobilizadas assumem configurações mais lingüísticas, como ocorrem em "o conhecimento prévio de outros textos" e "relações a outros textos". As duas últimas seqüências mobilizadas pela alfabetizadora configuram uma ancoragem didática do objeto, como ocorrem em "está sempre ligando" e "explorar com o aluno informações parecidas".

A primeira seqüência definidora "conhecimento prévio de outros textos", apesar de um acréscimo ao conjunto das seqüências definidoras manifestadas nos textos formadores, não configura, a nosso ver, uma mudança de ancoragem do objeto em um repertório próprio e familiar dos sujeitos, tal como se espera nos estudos de representações sociais (MOSCOVICI, 2003). A seqüência "conhecimento prévio" simboliza e estabiliza uma posição muito forte e aceita na academia, a de que a intertextualidade é um fenômeno cumulativo (KLEIMAN; MORAES, 2001), ou seja, quanto mais conhecemos os textos, mais podemos compreender novos textos. Finalizando, o enunciado do texto escrito é desestabilizado, gera uma ancoragem enunciativa marcada pelo embreante de posse "meu", em "meu entendimento", mas tudo isso ocorre sem necessariamente apagar ou ameaçar a representação simbólica e a significação acadêmica da definição de intertextualidade.

$\mathrm{Na}$ segunda seqüência, a 'intertextualidade' é definida como sendo a "relação entre os textos". Essa seqüência, conforme já analisamos no item 3, se estabiliza nos enunciados definidores dos textos escritos formadores, aqui analisados, assim como em diversos enunciados definidores da intertextualidade, que são divulgados através de textos e obras de divulgação científica da lingüística do texto e da análise do discurso. 
Considerando essas duas primeiras seqüências lexicais definidoras, podemos dizer, como o fez Py (2000), que a representação social de objeto da ciência, a sua ancoragem no senso comum, nos usos cotidianos, pode não apagar por completo a sua vinculação a uma rede de referências já instituída, ou seja, as posições amplamente difundidas na ciência e na universidade acerca dos objetos. Essas posições, por sua vez, compõem o repertório de saberes e a história de formação da alfabetizadora.

$\mathrm{Na}$ terceira e quarta seqüências, a 'intertextualidade' é definida como sendo a "ligação entre os textos" e como sendo a existência de "informações parecidas" entre um texto e outro. Nas referidas seqüências, a definição de intertextualidade é manifestada por intermédio da inserção de novos elementos lingüísticos como ocorrem, especialmente, em "é está sempre ligando um texto ao outro" e "outra informação parecida com aquele texto que está lendo". Se focalizarmos essa inserção, no interior do enunciado definidor da alfabetizadora, podemos dizer que são fenômenos de anáfora indireta (KOCH, 2002), que se configuram, por exemplo, pelo emprego das seqüências lexicais anafóricas "informações parecidas" e "ligações entre textos" para retomar, por associação, a seqüência anterior "relações entre os textos". Entretanto, se considerarmos as operações lingüísticas de retextualização do objeto do discurso, do escrito formador para o texto oral da alfabetizadora, como é o projeto deste artigo, é possível assegurar que se trata de um fenômeno de instabilidade categorial (MONDADA; DUBOIS, 2003) motivado pela especificidade do uso oral e ordinário, como sinalizamos anteriormente, gerando uma nova ancoragem do objeto da retextualização.

Nesse sentido, podemos assegurar que as seqüências metafóricas: "está sempre ligando" e "informações parecidas", diferentemente das seqüências: "conhecimento prévio dos textos" e "relação entre os textos", não são previamente textualizadas em algum enunciado formador, e por isso não podemos enquadrá-las diretamente como um fenômeno de retextualização de conceitos da escrita para a oralidade, sem que a retextualização seja enriquecida com os estudos das representações sociais como objeto das práticas discursivas.

Podemos dizer, assim, que, nesse caso, temos uma ancoragem ou acomodação do objeto com o apoio de novas metáforas ou a partir de 
uma lexicalização menos estranha e mais familiar para a alfabetizadora e mais próxima de suas práticas discursivas cotidianas. No nosso entendimento, trata-se de uma situação em que o quadro simbólico definidor do conceito da 'intertextualidade' é desestabilizado e novas imagens são acrescidas, um indicador da apropriação no e pelo uso específico que se faz do conceito (PY, 2004; DE CERTEAU, 1996). A descrição do uso específico é marcada principalmente pela ancoragem da definição de 'intertextualidade' na seqüência "eu venho sempre explorando com o educando se eles já ouviram informação parecida". Nesse caso, temos uma ancoragem que caracteriza o modo de dizer e de definir em um uso social da intertextualidade e a partir de um lugar específico, ou seja, a partir de um uso em sala de aula que implica em uma atualização didática do conceito. Trata-se, a rigor, de uma ancoragem enunciativa (MAINGUENEAU, 2001) sob o efeito didático, portanto, de uma ancoragem didática, um fato ainda pouco explorado nos estudos da enunciação e despercebido nos estudos de cognição social.

Uma imagem semelhante ao que ocorre nessa ordem de apropriação do conceito é feita por Jacobi (1984) quando descreve o "efeito cascata" implicado na reformulação científica. Em um mesmo enunciado, por exemplo, no esforço de se fazer entender, o agente reformulador (PEYTARD, 1984) faz reformulações sucessivas, incorporando novo léxico e enriquecendo a formulação de fonte por meio de metáforas e outras variações da linguagem cotidiana, gerando uma representação social do conceito da ciência (SANTOS, 2005; SANTOS, 2006).

A representação social concebida como objeto dos discursos e das práticas discursivas (PY, 2000) pode conter uma representação de referência (RR), determinada pelas condições amplas de formação, como, por exemplo, a inserção em práticas de leitura universitárias que interdita e posiciona os sujeitos, mantendo-os em diálogo com os discursos especializados. No entanto, essa mesma representação social, sendo exaustivamente examinada, neste estudo, também contém uma representação de uso (RU), determinada pelas condições sociais mais imediatas e que revela as posições, identificações e particularidades dos sujeitos acerca dos conceitos formadores e relevantes na formação. Neste sentido, o estudo do efeito da ciência e da escrita ou, por outro 
lado, da resistência ao seu quadro simbólico deve ser feito levando em conta o equilíbrio entre estabilização e desestabilização do objeto das representações na linguagem em uso.

Com base nessas considerações, podemos apontar um dos limites da retextualização enquanto conceito operacional nos estudos do impacto dos textos acadêmicos e das categorias especializadas na formação do alfabetizador e, evidentemente, podemos destacar a relevância do conceito de representação social como um pressuposto complementar para a pesquisa sobre o letramento, sobretudo quando este conceito inclui um foco nas práticas sociais reais e específicas, assim como as réplicas e a posições do leitor, as interfaces com a cultura oral e as manifestações cotidianas da escrita e dos objetos de formação.

\section{CONSIDERAÇÕES FINAIS}

Este trabalho coloca em evidência algumas reflexões que nos parecem relevantes para os estudos da formação lingüística do alfabetizador em contextos distantes dos grandes centros de produção e circulação da escrita.

Em primeiro lugar, salienta o fato de que as agências de letramento, em especial as Universidades, divulgam as definições teóricas da lingüística do texto e tais definições passam a constituir o repertório de saberes dos alfabetizadores, inclusive os que estão atuando e em formação, por exemplo, em pequenas cidades do semi-árido baiano. Cada vez mais o grande público está tendo acesso aos gêneros acadêmicos e aos conceitos que são divulgados por meio deles. Esse fato, sem dúvida, sugere que a formação continuada deve considerar a heterogeneidade dos modos de recepção e aprendizagem das definições novas e especializadas, que se revela, por exemplo, nas práticas de letramento do professor alfabetizador. Nesse sentido, os formadores devem sempre levar em conta os conflitos e diálogos existentes entre teoria e prática, entre escrita e oralidade e entre as definições científicas e as representações sociais dos grupos para quem a formação se destina. Além disso, devem questionar, também, como a linguagem e os 
conhecimentos locais contribuem para a inserção desses grupos em práticas letradas de prestígio na sociedade.

Em segundo lugar, a avaliação do impacto dos cursos de formação em serviço, nesses contextos, não se deve limitar aos usos de escrita decorrentes das demandas acadêmicas, privilegiando o aprendizado de definições teóricas manifestadas por escrito. É necessário, também, que as agências formadoras, incluindo a universidade, ampliem a avaliação do impacto da formação lingüística e universitária do alfabetizador, levando em consideração as ações no local de trabalho e, a rigor, o uso das definições nas situações de ensino e nas manifestações orais.

Como lembram Michel de Certeau e Luce Giard, a propósito de uma ciência prática da singularidade (DE CERTEAU; GIARD, 1996), o conhecimento ensinado somente se torna aprendido quando o aprendiz consegue colocá-lo em sua linguagem oral, em suas práticas diárias, e quando esse aprendiz pode efetivamente resolver problemas em seu cotidiano, fortalecido pela posse desse conhecimento.

Nesse sentido, a nossa expectativa é de que esta investigação contribua para outros projetos que desejem pesquisar o saber local de alfabetizadores em situação de formação lingüística ou outra formação conceitual relevante. Em outros termos, esta pesquisa deve contribuir para a elaboração e execução de projetos que pretendam estudar o letramento situado como um produto da comunicação intercultural, isto é, como um produto do diálogo entre os saberes teóricos e os saberes gerados na ação docente, e para a elaboração e execução de projetos que visem à transformação das práticas escolares de ensino através de modelos menos elitistas de formação continuada e em serviço.

\section{REFERÊNCIAS}

ABRIC, J.-C. Pratiques sociales et représentations. Paris: PUF, 1994.

BREY, C. Les travaux pratiques de réformulation. Langue Française, Paris : Larousse, n. 64, p. 68-80, décembre 1984. 
BARTON, D.; HAMILTON, M. Local literacies: reading and writing in one community. London; New York: Routledge, 1998.

BRANDÃO, H. N. Introdução à análise do discurso. Campinas: Edunicamp, 1996.

CAVALCANTI, M. AILA 1996 e um estado da arte em microcosmo da Lingüística Aplicada. In: SIGNORINI, I.; CAVALCANTE, M. (Orgs.).

Lingüística Aplicada e transdisciplinaridade. Campinas: Mercado de Letras, 1998.

DE CERTEAU, M. A cultura no plural. Tradução de Enid Abreu Dobránszky. Campinas, SP: Papirus, 1995.

; GIARD, L.; MAYOL, P. A invenção do cotidiano - 2: morar, cozinhar. Tradução de Ephraim Ferreira Alves e Enid Abreu Dobránszky. Petrópolis, RJ: vozes, 1996.

ERICKSON, F. Métodos cualitativos de investigación sobre la enseñanza. In: MERLIN, C. W. (Org.). La investigación de la enseñanza II: métodos cualitativos y de observación. Barcelona: Paidos, 1989.

Prefácio. In: COX, M. I. P.; ASSIS-PETERSON, A. A. A. (Orgs.).

Cenas de sala de aula. Campinas, SP: Mercado de Letras, 2001.

GOODY, J.; WATT, I. As conseqüências do letramento. São Paulo: Paulistana, 2006.

JACOBI, D. Du discours scientifique, de sa réformulation et de quelques usages sociaux de la science. Langue Française, Paris: Larousse, n. 64, p. 68-80, 1984.

JODELET, D. Representações Sociais: um domínio em expansão. In:

(Org.). As representações sociais. Tradução de Lílian Ulup. Rio de Janeiro: Eduerj, 2001.

KLEIMAN, A. Os significados do letramento: uma nova perspectiva sobre a prática social da escrita. Campinas: Mercado de Letras, 1995.

O estatuto disciplinar da Lingüística Aplicada: o traçado de um

percurso, um rumo para o debate. In: SIGNORINI, I.; CAVALCANTE, M. (Orgs.). Lingüística Aplicada e transdisciplinaridade. Campinas: Mercado de Letras, 1998.

; MORAES. S. E. Leitura e interdisciplinaridade: tecendo redes nos projetos da escola. Campinas, SP: Mercado de Letras, 1999. 
KOCH, I. V. O texto e a construção dos sentidos. São Paulo: Contexto, 1997.

Desvendando os segredos do texto. São Paulo: Cortez, 2002.

LOFFLER-LAURIAN, A. M. Langue Française, Paris: Larousse, n. 64: "Vulgarização scientifique: formulation, reformulation, traduction", 1984.

Typologie des discours scientifiques: deux approches. Études de Linguistique Appliquée, Paris: Didier Érudition, n. 51, p. 8-20, JuilletSeptembre 1983.

MAINGUENEAU, D. Análise de textos de comunicação. São Paulo: Cortez, 2001.

MARCUSCHI, L. A. Da fala para a escrita: atividades de retextualização. São Paulo: Cortez, 2001.

MATÊNCIO, M. L. Atividade de (re)textualização em práticas acadêmicas: um estudo sobre o gênero resumo. Scripta, Belo Horizonte, n. 11, p.109-122, 2003.

MESARANI, S. O intertexto escolar: sobre a leitura, a aula e redação. São Paulo: Cortez, 2002.

MONDADA, L.; DUBOIS, D. Construção dos objetos de discurso e categorização: uma abordagem dos processos de referenciação. In:

CAVALCANTE, M. M.; RODRIGUES, B. B.; CIULLA, A. (Orgs.).

Referenciação. São Paulo: Contexto, 2003.

MOSCOVICI, S. La psychanalyse, son image et son public. Paris: Presses Universitaires de France, 1976.

Das representações coletivas às representações sociais. In: JODELET, D. (Org.). As representações sociais. Tradução de Lílian Ulup. Rio de Janeiro: Eduerj, 2001.

Representações sociais: investigações em psicologia social. Tradução

de Pedrinho A. Guareschi. Petrópolis, RJ: Vozes, 2003.

PEYTARD, J. Problématique de l'altération des discours: réformulation et transcodage. Langue Française, Paris: Larousse, n. 64: "Vulgarisation scientifique: formulation, réformulation, traduction", p.17-28, 1984.

PY, B. Analyse conversationnelle et représentations sociales: unité et diversité de l'image du bilinguisme. Tranel, Neuchâtel, n. 32, p. 5-20, 2000.

Pour une approche linguistique des représentations sociales.

Langages, n. 154, p. 6-18, 2004. 
RIEGEL, M. Définition directe et indirecte dans le langage ordinaire: les énoncés définitoires copulatifs. Langue Française, Paris: Laurosse, n. 73, p. 29-53, 1987.

SANTOS, C. B. A construção do conceito de coerência textual por professores em formação. Trabalhos em Lingüística Aplicada, Campinas, n. 41, p. 91 103, 2003.

- A construção da definição de pedagogia progressista pelo professor em formação. Revista da FAEEBA: Educação e contemporaneidade, Salvador, v. 15, n. 26, jul./dez. 2006.

Um assunto puxa o outro: a representação da coerência textual na formação do alfabetizador. Tese (Doutorado em Lingüística Aplicada) UNICAMP, Campinas, 2005.

VELOSO, A. S. A construção de conceitos da lingüística textual na oralidade do professor. Projeto (Iniciação científica) - PICIN, UNEB, 2006.

Recebido em 16/08/08. Aprovado em 23/09/08.

Title: Intertextuality in the reading of a literacy teacher

Author: Cosme Batista dos Santos

Abstract: This article presents a study on the linguistic and cognitive mechanisms involved in the construction of the definition of intertextuality by a literacy teacher in training. We assume that the retextualization of written scientific and pop science texts implies the reformulation, appropriation and social representation of the theoretical objects due to the specific aspects of the enunciative context. Therefore, in this perspective, the analysis of a specific literacy event of teacher education, aiming at the teaching and learning of theoretical concepts or definitions, can be oriented by the following question: what are the linguistic mechanisms used by teachers in training at university level to make theoretical notions more familiar? Thus, this analysis aims at broadening previous findings on the social representations of theoretical terms by teachers in training. The present discussion explores the effect of oral discourses and of personal experiences on the learning of scientific concepts.

Keywords: literacy; retextualization; social representations; enunciation; intertextuality.

Titre: L'intertextualité dans la lecture de l'aphabétisatrice

Auteur: Cosme Batista dos Santos

Résumé: Cet article présente une étude des mécanismes linguistiques et cognitifs compris dans la construction de la définition de l' 'intertextualité' par un professeur qui fait de la littératie en formation. Le présupposé adopté est celui qui dit que la retextualisation de textes écrits de la science et de la divulgation scientifique dans les 
événements de formation engage une reformulation, appropriation et représentation sociales des objets théoriques en fonction des particularités du contexte énonciatif. Dans cette perspective, cependant, l'analyse d'un événement de littératie spécifique dans la formation du professeur, qui vise l'enseignement-apprentissage de concepts ou de définitions théoriques, peut être orienté dans la question suivante: quels sont les mécanismes linguistiques employés par le professeur en formation pour que les notions théoriques de l'Université soient plus familières? De cette façon, cette analyse peut être développée avec l'objectif d'étendre des découvertes antérieures sur la représentation sociale de termes théoriques realisée par le professeur. Il s'agit d'une discussion sur l'action de faire part de l'oralité et de l'expérience dans l'apprentissage de la définition spécialisé.

Mots-clés: littératie; retextualisation; représentation sociale; énonciation; intertextualité .

Título: La intertextualidad en la lectura de la alfabetizadora

Autor: Cosme Batista dos Santos

Resumen: Este artículo presenta un estudio de los mecanismos lingüísticos y cognitivos envueltos en la construcción de la definición de la 'intertextualidad' por una profesora alfabetizadora en formación. El supuesto adoptado es el de que la retextualización de textos escritos de la ciencia y de la divulgación científica en los eventos de formación implica en reformulación, apropiación y representación social de los objetos teóricos en función de las particularidades del contexto enunciativo. En esa perspectiva, por lo tanto, el análisis de un evento de literacia específico de la formación del profesor, que visa al enseño-aprendizaje de conceptos o de definiciones teóricas, puede ser orientada por la siguiente cuestión: ¿cuales los mecanismos lingüísticos empleados por el profesor en formación para tornar más familiares las nociones teóricas en la Universidad? De ese modo, ese análisis puede ser desarrollado con el intuito de ampliar descubiertas anteriores sobre la representación social de términos teóricos realizada por el profesor. Se trata de una discusión sobre la participación de la oralidad y de la experiencia en el aprendizaje de la definición especializada.

Palabras-clave: literacia; retextualización; representación social; enunciación; intertextualidad. 